\title{
Dietary Patterns, Nutritional Knowledge and Status of Adolescents in Lagos, Nigeria.
}

Foluke Adenike Olatona ( $\square$ folaton@gmail.com )

College of Medicine, University of Lagos https://orcid.org/0000-0002-7766-0117

Precious Ifeoma Ogide

University of Lagos College of Medicine

Ebunoluwa Temiloluwa Abikoye

University of Lagos College of Medicine

Oluwafemi Temitayo llesanmi

Obafemi Awolowo University Teaching Hospital Complex

Kelechi Ebere Nnoaham

University of Plymouth Faculty of Health and Human Sciences

Research article

Keywords: Adolescents, dietary habits, nutritional knowledge, nutritional status

Posted Date: March 19th, 2020

DOI: https://doi.org/10.21203/rs.3.rs-18023/v1

License: (c) (1) This work is licensed under a Creative Commons Attribution 4.0 International License.

Read Full License 


\section{Abstract}

Background Adolescents in low- and middle-income countries, such as Nigeria, are at increased risk of under-nutrition and overnutrition. This study assessed this risk by examining the dietary patterns, nutritional knowledge and status of adolescents in Lagos state of Nigeria.

Methods A descriptive cross-sectional study in which six hundred and eighty-two (682) adolescents were selected from their communities using multistage sampling technique. Nutritional knowledge and dietary patterns were ascertained using structured, self-administered questionnaires and anthropometric measurements were taken to determine nutritional status. Data was analyzed using Epi-Info version 7.2.3.1 computer software. Chi-square was used to test for association between categorical variables and p-values $\leq 0.05$ were considered statistically significant. WHO Anthro-Plus was used to evaluate nutritional status.

Results The mean age of the adolescents was $13.6 \pm 2.3$ years. Only $12.0 \%$ of them had good level of nutritional knowledge with the males having significantly higher levels. Dietary pattern and diversity were poor with the majority consuming refined cereals $(73.5 \%)$, salty snacks/high fat foods $(69.6 \%)$ and carbonated soft drinks (46.8\%) while only $9.7 \%$ took adequate amount of fruits and vegetables daily. Prevalence of undernutrition was $5.4 \%$ while that of overweight and obesity were $10.7 \%$ and $5.3 \%$ respectively. More females were obese compared with the males. Sex, age, educational status, source of information, daily consumption of snacks, infrequent intake of fruits and vegetables, nutritional knowledge, food habits and dietary diversity were statistically significantly associated with nutritional status of adolescents in the positive direction $(p \leq 0.05)$.

Conclusions Nutritional knowledge and dietary patterns were poor while overweight and obesity are higher than previously reported in the region; especially among the females. Adolescent nutrition intervention programmes addressing weight control especially among females is needed in Lagos.

\section{Background}

The co-existence of two different forms of malnutrition creates a double burden of nutrition-related ill health in specific populations. Adolescents in low-and middle-income countries, such as Nigeria, are at increased risk of under-nutrition (because of inadequate food intake, irregular meals consumption especially skipping breakfast) and overnutrition because of overnutrition because of over-consumption of foods that are high in calorie and fats but poor in nutrients. ${ }^{1,2}$

Social pressures to achieve a distorted body image is creating under nutrition among some groups of adolescents. ${ }^{3}$ On the other hand, overweight and obesity continue to increase due to nutrition transition to energy and lipid-rich diets and decrease in physical activity, especially among urban adolescents. ${ }^{3}$ Common eating behaviours include snacking, skipping meals, eating out, and consuming foods that are high in fats and carbohydrates. ${ }^{3,4}$ 
Irregular meal patterns are associated with obesity and overeating is linked with breakfast skipping. 5,6

The global prevalence of underweight (thinness) among adolescents is $8.4 \%$ for girls and $12.4 \%$ in boys. 7 According to the Global School-Based Student Health Survey, about 4\% of girls aged 13-15 years of age are underweight, although $>10 \%$ of surveyed girls are underweight in countries like Mauritius, Sudan, Bangladesh, Maldives, Cambodia and Vietnam. (8) In 2016, the mean BMI estimates for youths aged 1019 in South Asia, South East Asia, East Africa, West Africa and Central Africa were $<20 \mathrm{~kg} / \mathrm{m}^{2}$ for both male and female adolescents. 7

The percentage of overweight adolescents has more than tripled since 1980, with 17\% of adolescents between ages 12-19 being considered overweight. Globally, the prevalence of obesity (BMI > 2SD BMI for age $Z$ score) has risen from < 1\% in 1975 to $>5 \%$ in girls and nearly $8 \%$ in boys age 5-19 in 2016 . 7,9 Malnutrition increases health care costs, decreases productivity and slows economic growth, which can perpetuate a cycle of poverty and ill health. ${ }^{10,11}$ Long-drawn undernutrition leads to energy and protein deficiency, which might result in an inhibition of physical and intellectual development, cognitive functions impairment, disorders in immune system and poor obstetrics outcome. ${ }^{12}$ It could also affect social and psychological development. Moreover, overweight increases the risk of Non-Communicable Chronic Diseases such as cardiovascular diseases, different kinds of disabilities and mortality, later in life. ${ }^{13,14}$

Adolescence offers the last opportunity to intervene and recover growth that faltered in childhood and support growth spurt. ${ }^{15}$ Adolescents have high nutritional needs but usually engage in risky habits such as unhealthy eating which affect their immediate health and have significant impact on their health in adulthood. About $40 \%$ of adult deaths in developing countries and $70-80 \%$ of deaths in industrialized countries are linked to attitudes and behaviours adopted during adolescence. ${ }^{1,9}$ Research suggests that adequate level of nutritional knowledge is related to optimal nutritional behaviours while dietary habits affect nutritional status. ${ }^{16}$ Dietary habit is one of the modifiable risk factors for obesity in childhood and adolescence. ${ }^{17}$ In Nigeria, the prevalence of underweight among adolescents range from $13.5-37.1 \%$, while that of overweight and obesity range from 7.4 to $13.2 \%$ and 2.6 to $4.4 \%$ respectively. ${ }^{10,19}$ Over the years, the presumption that adolescents are less susceptible to disease and suffer relatively fewer lifethreatening conditions has limited research interest in this group, while more attention has been given to children. Hence, there is a paucity of data on adolescent nutrition in Nigeria. ${ }^{20}$ Adolescents however constitute a significant population (almost one fifth of Nigerian population) that represent a huge potential workforce whose health affect the nation socially and economically. Adolescents can learn and adopt healthy habits to create a strong foundation for healthy lifestyles to improve quality of their lives in adulthood. Some studies have reported low level of nutritional knowledge, poor dietary patterns and nutritional status of adolescents in other parts of Nigeria but there is limited information about these parameters among adolescents in Lagos State. ${ }^{18,19,21}$ Although Lagos, in terms of land mass, is the smallest State in Africa's most populous country, its cosmopolitan nature, economic productivity and high population density make it an effective window into the lived experiences of Sub-Saharan African 
populations, particularly in terms of how the nutritional status of adolescents predicts future health and healthcare burdens. This study therefore determined the nutritional knowledge, dietary patterns, nutritional status and associated factors among adolescents in Lagos state.

\section{Methods}

A descriptive cross-sectional study was conducted among adolescents in Lagos Metropolitan area. Male and female adolescents between 10-19 years were included in the study. The sample size determined using Cochran's formula was 400 but 682 adolescents were recruited into the study.

Sampling technique: A multi-stage sampling technique was used to determine the sample. Using simple random sampling technique, two local government areas (Somolu and Lagos Mainland) were selected from the twenty LGAs, four wards were selected from each LGA to obtain eight wards and three streets were selected from the list of streets in each ward to obtain twenty-four streets. All the eligible houses on each street were included in the study but only one adolescent was selected from each household using balloting method.

Data was collected using structured interviewer-administered questionnaire. A standard questionnaire was adapted for assessment of nutrition knowledge. ${ }^{22}$ Some non-local foods in the standard questionnaire were replaced with local foods with similar nutrient profiles. Food frequency questionnaire was used to determine dietary habits. Nutrient intake was assessed by using non-quantifiable 24- hour diet recall. Anthropometric measurements were taken and analyzed according to WHO standard to determine the Body Mass Index. ${ }^{23}$

Six research assistants were trained successfully for data collection. The questionnaire was pretested in Oshodi-Isolo LGA and the results were used to adjust the questionnaire before data collection.

Data analysis: Data was analyzed using EPI INFO epidemiological software package (version 7.2.3.1). The socio-demographic characteristics were analyzed using descriptive statistics. Relevant summary statistics were generated for the variables. The chi-square test was used to determine association between categorical variables, and $p$ values of $\leq 0.05$ were considered as statistically significant.

Malnutrition was determined based on the WHO classification/ BMI cut offs as follows: $\geq 17.0$ to $<18.5=$ Grade 1 thinness / mild malnutrition; $\geq 16.0$ to $<17.0=$ Grade 2 thinness / moderate malnutrition; $<16.0=$ Grade 3 thinness $/$ severe malnutrition, $\geq 18.5$ to $<25.0=$ Normal nutrition; $\geq 25.0-<30=$ overweight; $\geq 30$ $=$ obesity. ${ }^{24}$

$\mathrm{BMI} Z$ scores were calculated for each adolescent based on their age in months, BMI and gender. Z score expresses the anthropometric value (BMI in this case) as a few standard deviations below or above the reference mean/ median value, and is classified as: - - 3SD - Severe thinness; -3SD to <- 2SD - Thinness; - 2SD to 1 SD - Normal; $1 S D$ to 2 SD = Overweight; > 2SD - Obese. ${ }^{24}$ 
The scores of nutritional knowledge ranged from $0-15$. Those who scored 0-5 were classified as having poor knowledge, 6-10 as having fair knowledge while those who scored 11-15 were regarded as having good level of knowledge.

The dietary patterns were analyzed using frequency tables. The non-quantifiable 24-hour dietary recall was analyzed based on the dietary diversity. Participants who consume four (4) out of the seven (7) classes of food were classified as having adequate dietary diversity, while those who consumed below four (4) classes of food were classified as having inadequate dietary diversity.

\section{Results}

\section{Socio-demographics characteristics of the adolescents}

Most of the respondents were early adolescents (63.9\%) and the mean age of the participants was $13.6 \pm 2.3$ years. Most of them (94.9\%) lived with their parents at the time of the study. (Table 1)

\section{Respondents' nutritional knowledge}

Majority of the adolescents, $69.8 \%$ (Cls $64.5-74.7 \%$ ) knew the six classes of food but only $17.2 \%$ (Cls $33.1-43.9 \%$ ) knew that balanced diets must contain all the nutrients in adequate amount. Few adolescents, $15.8 \%$ (Cls 5.6-11.8\%) knew that food could either cause disease or improve health. The most prominent source of nutritional information for the participants was other family members (54.1\%). Only $12.0 \%$ (Cls $17.1-26.3 \%$ ) of the adolescents had overall good nutritional knowledge about food groups, healthy food choices and diet related diseases. (Table 2)

\section{Dietary Patterns}

Processed cereal including white rice was the commonest cereal consumed by the adolescents daily (73.5\%). Fruits and vegetables (15.7\%), roots and tubers (12.4\%), legumes $(13.4 \%)$ were rarely eaten whereas $46.8 \%$ drank carbonated drinks daily. Only $9.7 \%$ took adequate amount of fruits and vegetables (F\&V) which is $400 \mathrm{~g}$ or five servings per day. (Figure 1)

\section{Nutritional Status of the adolescents}

Prevalence of overweight and obesity were $10.7 \%$ and $5.3 \%$ respectively while underweight was $5.4 \%$.

(Figure 2)

\section{Factors associated with nutritional knowledge}

Age, sex, educational level and source of information were significantly associated with the nutritional knowledge of the adolescents; male, younger adolescents, senior secondary school adolescents and those who obtained information from their families had better nutritional knowledge $(p \leq 0.05)$. (Table 3 ) 
Sex, age, living with parents were significantly associated with the nutritional status of the adolescents $(p \leq 0.05)$. Prevalence of overweight and obesity were higher among the girls compared with the boys. Prevalence of underweight, overweight and obesity were higher among the older adolescents (24(9.8\%), $27(11.0 \%)$ and $21(8.5 \%)$ respectively compared to the younger ones.

The overall level of nutritional knowledge was significantly associated with the nutritional status of the adolescents, $(P \leq 0.05)$. Most of the adolescents who had good nutritional knowledge were within the normal BMI range. Poor level of nutritional knowledge was associated with higher prevalence of underweight, 28(20.4\%), overweight 22(16.1\%) and obesity, 16(11.7\%).

Infrequent intake of fruits and skipping meals to control weight were positively associated with higher prevalence of overweight and obesity while dieting to control weight was positively associated with underweight. However, there was no statistically significant association between the number of main meals eaten per day and nutritional status of the participants. (Table 4)

\section{Discussion}

Most of the respondents' parents had at least secondary education (78.5\%). This is consistent with the findings of a similar study in Ibadan, Nigeria where $89.2 \%$ and $94.6 \%$ of the mothers and fathers had at least secondary education. ${ }^{25}$

Less than one third $(31.0 \%)$ of the adolescents had good knowledge of balanced diet but the majority $(76.1 \%)$ knew the common food sources of energy and protein. This agrees with a similar study in Abuja municipal area, wherein $34.8 \%$ of the adolescents had good knowledge of balanced diet. ${ }^{26} \mathrm{It}$ is possible that the adolescents had learnt about common food sources in school through subjects like physical and health education, home economics as well as food and nutrition. In contrast, less than half of the adolescent girls in rural Bangladesh, knew common food sources of energy and protein. ${ }^{15}$ The higher knowledge among adolescents in Lagos could be because Lagos is an urban area where adolescents are probably more exposed to media adverts, television and internet compared to 'rural Bangladesh'.

Overall nutritional knowledge was poor; only $12.0 \%$ of the adolescents had good level of overall nutritional knowledge. This is consistent with the report of a similar study in Sokoto, Nigeria where only $29 \%$ of adolescents had good level of nutritional knowledge. ${ }^{27}$ This implies that Nigerian adolescents don't have substantial knowledge and understanding of healthy food choices, energy and nutritive values of foods and dietary related diseases. Detailed explanation of healthy food choices, energy and nutritive values of foods and dietary related diseases maybe absent from the school curriculum. On the contrary, a Tehranian study reported good nutritional knowledge among $82 \%$ of the girls and $75 \%$ of the boys. ${ }^{28}$ This could be because adolescents in Asia are more exposed than those in Nigeria. Good nutritional knowledge is important because it usually has a positive influence on healthy food choices and health. ${ }^{29}$ This was demonstrated in this study because the level of knowledge was significantly associated with the nutritional status of the adolescents. Most of the adolescents who had good nutritional knowledge 
were within the normal range of Body Mass Index. This finding similar to that of another study in India where nutritional knowledge had great impact on the health status of adolescents. ${ }^{30}$

According to this current study, sex and age were positively associated $(p<0.05)$ with level of nutritional knowledge. The males and younger adolescents exhibited better nutritional knowledge than the females and older adolescents. This is similar to the findings from another study in rural Bangladesh ${ }^{15}$ where age, and other socio-demographic characteristics were positively associated with nutritional knowledge. It however contrasts with the report from a similar study in Sokoto state, Nigeria ${ }^{28}$ where the females had better overall nutritional knowledge than males. This current research shows that females do not always have better nutritional knowledge.

Various forms of malnutrition have been associated with adolescents' dietary patterns which make them predisposed to obesity and non-communicable diseases. Majority (84.9\%) of adolescents in this study had 3-4 main meals per day. This could be because they lived with their parents who monitor their feeding. This finding is corroborated by another report from urban Baroda, India, where $55 \%$ of the adolescents took regular meals 3 times a day, (4) but contrasts with the report from adolescent girls in Saudi-Arabia ${ }^{31}$ where $44.7 \%$ of the adolescents had $2-3$ main meals in a day and

Skipping of breakfast was reported among 33.0\% of the adolescents and done five times more often compared with dinner (5:1). This is consistent with another report from Saudi-Arabia where $40.0 \%$ skipped breakfast and other Nigerian studies where the rate of breakfast skipping is higher than lunch and dinner. ${ }^{31,32}$ However, in India $55 \%$ of adolescents have a good habit of taking regular meals thrice a day and did not skip a single meal in a week. ${ }^{4}$ Adolescents generally have poor habits of breakfast skipping irrespective of their geographical location. Some reasons for missing meals as explored by other studies include little time for meal preparation, ill health, lack of appetite, or disliking the food served. ${ }^{27}$

Adolescents' concern about body image has been linked with breakfast skipping and social pressures to achieve a distorted body image, is creating malnutrition among some groups of adolescents. ${ }^{17}$ About $45 \%$ of rural adolescents in India suffer from under-nutrition with Body Mass Index (BMI)<-2SD. ${ }^{33}$ Irregular meal patterns and breakfast skipping are associated with obesity. ${ }^{5,6}$ The consequences of poor dietary habits such as skipping breakfast, include poor academic performance on standardized tests, absenteeism and tiredness. ${ }^{34}$

Daily consumption of snacks (69.6\%) and carbonated drinks (46.8\%) were common among the adolescents. These findings are similar to reports from Sokoto where $82.1 \%$ of the students reported daily consumption of snacks though a lower prevalence was obtained in Osun state (33.2\%). ${ }^{20,}{ }^{29}$ This finding agrees with a Ghana study where majority of adolescents were reported to have Sweet Tooth Patterns (STPs). ${ }^{35}$ Adolescents commonly indulge in unhealthy dietary practices. When adolescents skip meals, they often make poor decisions such as consuming less fruits and vegetables, buying fast foods or unhealthy snacks which lead to weight gain and ultimately diabetes and heart disease later in life. ${ }^{3}$ 
The WHO survey among Oman adolescents reported that some foods that were used for snacks included carbonated drinks (33.4\%) and fast foods (10\%), which mostly are purchased outside the home. This practice of snacks use is becoming more common in societies due to westernization and especially among those who spend long hours outside home. ${ }^{36}$

Dietary intake of adolescents in developing countries like Nigeria and Ghana is a major concern, because traditional diets (predominantly cereal and tuber based, fresh fruits and vegetables and foods low in fat) are gradually giving way to more westernized diets which lack diversity and are high in calorie. The reason for increased consumption of snacks can be because the adolescents have some amount of money available to them for daily spending, and that these unhealthy snacks and soft drinks are relatively affordable and comfortably fits in their budget.

Consumption of high-sugar, fat and salty snacks was high among the adolescents because of ready availability and affordability of the snacks. Consistent with previous studies, the choice of fast food among adolescents was influenced by taste, convenience and cost. Most fast foods with the qualities of good taste, convenience and low cost, usually have a high fat and sugar content but low fiber content which promotes obesity. ${ }^{36}$ Consumption of snacks is a general issue among adolescents irrespective of their countries or localities. Although snacking is not completely bad, the quality of snacks chosen is very important. Carbonated soft drinks are energy dense and have a high glycemic index. ${ }^{36}$ Some studies have linked high soft drink consumption rate to poor intake of calcium, vitamin $\mathrm{C}$ and increased risk of bon e fractures because of its acidity. ${ }^{36}$

Cereals especially rice (73.5\%) and pastries (69.6\%) were the most commonly consumed group of foods. This finding correlates with other studies from South-western Nigeria (76.5\%), Ethiopia (99.6\%) $(97.6 \%)$ and India (50\%) where rice and pastries were commonly consumed by adolescents compared with other foods. ${ }^{4,37,38}$ Refined cereals like processed rice and pastries have little or no fiber and contribute to the prevalence of obesity. They contribute significantly to the higher intakes of Advanced Glycation Endproducts (AGEs) which is associated with marginally greater weight gain. The top six food groups contributing to AGEs intake are cereals/cereal products, meat/processed meat, cakes/biscuits, dairy, sugar and confectionary and fish/shellfish. ${ }^{39}$

A higher proportion of older adolescents were underweight, overweight and obese compared with younger adolescents. This may be because many of the older ones engaged in dieting and skipping of meals compared with the younger adolescents. This finding is a contrast to the results obtained from similar studies in India and Ibadan, Nigeria where higher proportion of the younger adolescents were underweight $(p<0.001) .4,20$

Females had higher prevalence of overweight (13.9) and obesity (8.4\%) compared with males $(6.6 \%$ and $4.3 \%$ ) similar to the reports from Sokoto and Ethiopia studies. ${ }^{27,37}$ The higher prevalence of obesity among the girls may be related to weight gain that results from developmental changes and hormonal influences which necessitates beginning of menarche in females. In addition to the hormonal influences, 
gender roles particularly those requiring higher physical exertion can also affect weight. Boys participate more in physical activities which necessitate energy utilization compared with girls, thereby aiding expenditure of consumed calories, and reduction of fat accumulation. However, some other studies have reported contrasting reports wherein more boys had higher prevalence of overweight than girls (19.4 vs $13.2 \% ; p<0.05) .{ }^{4}$

Infrequent intake of fruits $(456,66.9 \%)$ and skipping meals to control weight $(254,38.7 \%)$ were positively associated with higher prevalence of overweight and obesity while dieting to control weight $(365,53.5 \%)$ was positively associated with underweight. However, there was no statistically significant association between the number of main meals eaten per day and nutritional status of the participants $(p=0.0508)$.

Only $9.7 \%$ of the adolescents consumed adequate fruits and vegetables ( $F \& V$ ) (400 g or 5 servings) daily. This is not surprising since only $27.0 \%$ of the adults in Lagos consumed an adequate amount of F\&V daily. Consumption of F\&V is usually lower among adolescents due to inadequate knowledge about their benefits, family practice of irregular fruits intake, dislike of the taste of some fruits and others. In this study, low consumption of fruits and vegetables was associated with overweight and obesity. This correlates with the report from a similar study in Benin City, where low consumption of fruits and vegetables was associated with overweight. ${ }^{32}$

Only $30.4 \%$ of the respoendents had high dietary diversity, similar to the report among Zimbabwe and Tehranian adolescents where less than $50 \%$ of adolescents had high dietary diversity. ${ }^{40}$ Based on the nine item FAO Dietary Diversity Score (WDDS); dietary diversity is regarded as high and more likely to meet micronutrient needs if four or more food groups are consumed per day whereas dietary diversity is poor if three or less food groups are consumed per day. ${ }^{41}$ In this study, good dietary diversity was associated with normal body mass index and decreased prevalence of underweight, overweight and obesity $(p<0.001)$. This correlates with the fact that adequate dietary diversity indicates that significantly higher intakes of most key nutrients are consumed and available for the body to maintain a normal nutritional status. ${ }^{42}$

Number of meals consumed per day was not associated with the nutritional status of the adolescents. This agrees with some other studies which have demonstrated that no of meals does not affect weight status but contrasts the findings in a similar study in Saudi-Arabia where $13.0 \%$ of those who consumed more than four meals per day were overweight and obese. ${ }^{31}$

Few adolescents, $5.4 \%$ were undernourished, $78.6 \%$ were of normal weight, while $10.7 \%$ and $5.3 \%$ were overweight and obese respectively. The prevalence of obesity among Lagos adolescents is quite higher

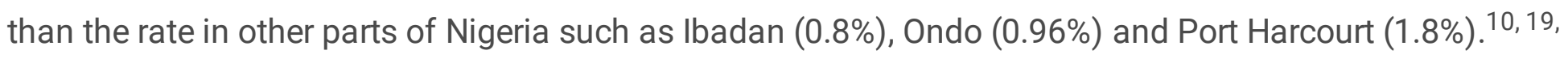
${ }^{43}$ Nutritional status of adolescents is very important, because they are highly susceptible to malnutrition which can have impact on their offspring in the future. ${ }^{44}$

\section{Conclusions}


Levels of nutritional knowledge and dietary patterns of adolescents in Lagos were poor while the prevalence of overweight and obesity are rising compared with past studies. Poor nutritional knowledge and dietary patterns as well as obesity favour increased risk of non-communicable diseases later in adult life.

\section{Limitations Of The Study}

Only chi-square test was employed in statistical analysis and this might not have been sensitive enough since many confounders could likely change the result of the association.

\section{Declarations}

Ethics approval and consent to participate: The study was conducted according to the guidelines laid down in the Declaration of Helsinki. Ethics approval was obtained from the Health Research and Ethics Committee of the Lagos University Teaching Hospital (Ref No: ADM/DCST/HREC/APP/3074) before commencing the study. Child assent was obtained from the participants while informed written consent was obtained from their parents before the study. Confidentiality was assured and maintained throughout the period of the study.

Consent for publication: "Not applicable"

Availability of data and material: The datasets used and analyzed during the current study are available from the corresponding author on reasonable request.

Competing interests: The authors declare that they have no competing interests

Funding: The research was funded by the authors

Authors' contributions: FO, PO and EA conceptualized and designed the study. PO, EA and FO acquired and interpreted the data. FO, PO, EA, OI and KN drafted the manuscript and critically revised it for important intellectual content. All authors read and approved the final manuscript.

Acknowledgements: The authors acknowledge the support of the chairmen of Somolu and Lagos Mainland Local Government Areas of Lagos State.

\section{References}

1. Gacek M. Dietary habits and locus of control assessed in middle school from the Malopolska region of Poland. Rocz Panstw Zakl Hig 2013;64(2):129-143.

2. Pederson TP, Meilstrup C, Holstein BE, Rasmussen M. Fruit and vegetables is associated with frequency of breakfast, lunch and evening meal: cross sectional study of 11,13 and 15 years olds. Int $\mathrm{J}$ of Beh Nut Phys Act 2012; 9:1-10. 
3. Dona Schneider. International trends in adolescent nutrition. Social Science \& Medicine 2000;51(6): 955-967.

4. Kotecha PV, Patel SV, Baxi RK. Dietary Pattern of School going Adolescents in Urban Baroda, India. Journal of Health, Population and Nutrition. 2013; 31(4):490-496.

5. Neimeier H, Raynor H, Lloyd-Richardson E, Rogers M, Wing R. Fast food consumption and breakfast skipping: Predictors of weight gain from adolescence to adulthood in a nationally representative sample. J Adolesc Health 2006;39(6):842-849. [http://dx.doi.org/10.1016/j. jadohealth.2006.07.001]

6. Keski-Rahkonen A, Kaprio J, Rissanen A, Virkkunen M, Rose RJ. Breakfast skipping and healthcompromising behaviours in adolescents and adults. Eur J Clin Nutr 2003;57(7):842853.http://dx.doi.org/10.108/sj.ejcn.1601618

7. Abarca-Gomez L. NCD risk factor collaboration (NCD- RisC): Worldwide trends in BMI, Underweight, Overweight and obesity from 1975 to 2016: a pooled analysis of 2416 population-based measurement studies in 128.9 million children, adolescents and adults. Lancet 2017;390(10113):2627-2642.

8. Askeer N. Global and regional trends in the nutritional status of young people: a critical and neglected age group. Ann N Y Acad Sci 2017; 1393:3-20.

9. Adolescent Health Services: Missing opportunities. Washington DC: National Academies Press (US); 2009. 2, Adolescent Health Status. Available at https://www.ncbi.nlm.nih.gov/books/NBK215414/ Accessed June 17, 2019.

10. Kola-Raji BA, Balogun MR, Odugbemi TO. A comparative study of nutritional status of adolescents from selected private and public boarding schools in Ibadan, Southwestern Nigeria. J Med Trop 2017;19(1):49-55.

11. World Health Organization: Malnutrition fact sheets. Available at https://www.who.int/newsroom/fact-sheets/detail/malnutrition/ (Accessed June 17, 2019)

12. Adolescent Nutrition. Public Health at a Glance. Available from http://web.worldbank.org/archive/website01213/WEB/0_CO-82.HTM (Accessed May 9, 2018)

13. Bartkowicz J, Mironiuk K. Assessment of selected nutritional behaviours among college adolescents from Pomerania province. Rocz Panstw Zakl Hig 2018; 69(4): 387-395.

14. Twig G. BMI in 2.3 million adolescents and CV death in adulthood. N Eng J Med 2016; 374:24302440.

15. Alam N, Roy SK, Ahmed T, Ahmed AM. Nutritional status, dietary intake, and relevant knowledge of adolescent girls in rural Bangladesh. Journal of Health, Population and Nutrition. 2010; 28(1): 86-94.

16. Miller LMS, Cassady DL. The effects of nutrition knowledge on food label use: A review of the literature. Appetite 2015; 92:207-216.

17. Onyiriuka N, Umoru D.D, and Ibeawuchi A.N. Weight status and eating habits of adolescent Nigerian urban secondary school girls. South African Journal. 2013;7(3):108-112. 
18. Mijinyawa MS, Yusuf SM, Gezawa ID, Musa BM, Uloko AE. Prevalence of thinness among adolescents in Kano, Northwestern Nigeria. Nigerian Journal of Basic and Clinical Services 2014; $11(1): 24-29$.

19. Mustapha RA and Sanusi RA. Overweight and obesity among in-school Adolescents in Ondo state, southwest Nigeria. African Journal of Biomedical Research 2013; 16: 205-210.

20. Olumakaiye MF. Prevalence of underweight: A matter of concern among adolescents in Osun state, Nigeria. Pakistan Journal of Nutrition 2008;7(3):503-508

21. Abdulkarim AA, Otunenye AT, Ahmed P, Shattima DR. Adolescent malnutrition: Prevalence and pattern in Abuja municipal area council, Nigeria. Nigeria Journal of Paediatrics 2014;41(2): 99.

22. Kliemann N, Wardle J, Johnson F, Croker H. Reliability and validity of a revised version of the General Nutrition Knowledge Questionnaire. Eur J Clin Nutr. 2016 ;70(10):1174-1180. doi: 10.1038/ejcn.2016.87. Epub 2016 Jun 1. PMID: 27245211; PMCID: PMC5014128.

23. World Health Organization. WHO STEPS Surveillance Manual. WHO Glob Report, Geneva. 2008;1453.

24. WHO 2007. Growth and reference data for 5-19 years. [online] Available at https://www.who.int>about>index4.

25. Omobuwa O, Alebiosu CO, Olajide FO, Adebimpe WO. Assessment of nutritional status of in-school adolescents in Ibadan, Nigeria. South African Family Practice 2014; 56(4):246-250.

26. Otuneye AT, Ahmed PA, Aniko 00, Abdulkarim AA. Relationship between dietary habits and nutritional status among adolescents in Abuja Municipal Area council of Nigeria. Niger J Paediatr 2017;44(3):128.

27. Essien E, Emebu PK, Iseh KR, Haruna MJ. Assessment of nutritional status and knowledge of students from selected secondary schools in Sokoto Metropolis, Sokoto State, Nigeria. African Journal of Food, Agriculture, Nutrition and Development 2014; 14(6):9454-68.

28. Mirmiran P, Azadbakht L, Azizi F. Dietary behavior of Tehranian adolescents does not accord with their nutritional knowledge. Public Health Nutrition Journal.2007; 10(9): 897-901.

29. Suneetha E, Mashael U, H Al S. Nutrition Knowledge and its Impact on Food Choices among the students of Saudi Arabia. IOSR Journal of Dental and Medical Sciences, 2014; 13(1):68-74.

30. Rani J, Tyagi R, Chahal S, Bhateri. Impact of nutritional knowledge status of adolescents on their health. International Journal of Innovations in Engineering and Technology (IJIET) 2013; 3(2):275278.

31. Waseem F, Nasser SMA, Ahmad LM. Assessment of Nutritional Status and its related factors among female adolescent girls: A school-based study in Arar city, Kingdom of Saudi Arabia. Int. J. Med. Res. Health Sci 2019; 8(2): 133-144

32. Onyiriuka AN, Ibeawuchi AN, Onyiwuke RC. Assessment of eating habits among adolescents in Nigerian Urban secondary school girls. Sri Lanka Journal of Child Health 2013; 42(1):20-26. 
33. Adolescent Nutrition. Nutrition and Well Being A- Available from http://www.encyclopedia.com/food/news-wires-white-papers-and-books/adolescentnutrition</food/news-wires-white-papers-and-books/adolescent-nutrition> (Accessed April 29, 2018).

34. Youth Risk Behaviour Surveillance System. 2013 [online] Available from URL:http://www.cdc.gov/healthyyouth/yrbs/index.htm. (Accessed 5th November, 2019).

35. Abdul-Razak A; Zakari A. Dietary patterns and associated factors of schooling Ghana adolescents. Journal of health, Pop and Nutr 2019;38:5.

36. Oman Global School-based Student Health Survey. [online] Available from URL: http://www.who.int/chp/gshs/oman_GSHS_country-report.pdf.2005. (Accessed 5th November, 2019).

37. Gali N, Tamiru D, Tamrat M. The emerging nutritional problems of school adolescents: overweight/obesity and associated factors in Jimma town, Ethiopia. Journal of Paed. Nurs. 2017; 35:98-104.

38. Melaku Y, Dirar A, Feyissa GT, Tamiru D. Optimal diet practice and nutritional knowledge of school adolescent girls in Jimma town, South/Western Ethiopia. Int. Journal of Adolescence and Youth. 2017; 23(3): 299-307.

39. Cordova R., Knaze, V., Viallon, V. et al. Dietary intake of advanced glycation end products (AGEs) and changes in body weight in European adults. Eur J Nutr (2019). https://doi.org/10.1007/s00394-01902129-8.

40. Limbers D, Cohen A, Gray B. Eating disorders in adolescent and young adult males: prevalence, diagnosis, and treatment strategies. Adolescent Health, Medicine and Therapeutics. 2018; 9: 111116.

41. Reese-Masterson A, Murakwani P. Assessment of adolescent girl nutrition, dietary practices and roles in Zimbabwe. Field Exchange 2016; 52:113. ennonline.net/fex/52/adolescentgirlnutrition

42. Lander RL, Hambidge KM, Westcott JE, Tejeda G, Diba TS, Mastiholi SC, Khan US, Garcés A, Figueroa L, Tshefu A, Lokangaka A, Goudar SS, Somannavar MS, Ali SA, Saleem S, McClure EM, Krebs NF, Group OBOTWFPNT. Pregnant Women in Four Low-Middle Income Countries Have a High Prevalence of Inadequate Dietary Intakes That Are Improved by Dietary Diversity. Nutrients. 2019;11(7):1560. doi: 10.3390/nu11071560. PMID: 31295916; PMCID: PMC6682861.

43. Adesuwa FA, Oliemen P, Ifeoma A, Nwadiuto AA. Weight status of adolescents in secondary schools in Port Harcourt using Body Mass Index (BMI). Ital J Pediatr.2012;38:31.

44. Singh JP, Kariwal P, Gupta SB, Singh AK, Imtiaz D. Assessment of nutritional status among adolescents: a hospital based cross - sectional study. Int J Res Med Sci.2014;2(2):620-624. 


\section{Tables}

Table I: Socio-demographics characteristics of adolescents in the study population 


\begin{tabular}{|c|c|c|}
\hline Variable & Frequency $(n=682)$ & Percentage (\%) \\
\hline \multicolumn{3}{|l|}{ Age in years } \\
\hline $10-14$ & 436 & 63.9 \\
\hline $15-19$ & 246 & 36.1 \\
\hline \multicolumn{3}{|l|}{ Sex } \\
\hline Female & 287 & 42.1 \\
\hline Male & 395 & 57.9 \\
\hline \multicolumn{3}{|l|}{ Education level } \\
\hline Junior secondary school & 349 & 51.2 \\
\hline Senior secondary school & 333 & 48.8 \\
\hline \multicolumn{3}{|l|}{ Religion } \\
\hline Christianity & 453 & 66.4 \\
\hline Islam & 229 & 33.6 \\
\hline \multicolumn{3}{|l|}{ Currently living with } \\
\hline Parents & 647 & 94.9 \\
\hline Other than parents & 35 & 5.1 \\
\hline \multicolumn{3}{|l|}{ Family Setting } \\
\hline Monogamous & 550 & 80.7 \\
\hline Polygamous & 132 & 19.3 \\
\hline \multicolumn{3}{|l|}{ Ethnic Group } \\
\hline Yoruba & 440 & 64.5 \\
\hline Igbo & 168 & 24.6 \\
\hline Hausa & 8 & 1.2 \\
\hline Others (Benin, Efik and so on) & 66 & 9.7 \\
\hline \multicolumn{3}{|l|}{ Father's Occupation } \\
\hline Civil Servant & 138 & 20.2 \\
\hline Highly Skilled Professional & 188 & 27.6 \\
\hline Business & 305 & 44.7 \\
\hline Petty Trading & 38 & 5.6 \\
\hline Academics & 13 & 1.9 \\
\hline \multicolumn{3}{|l|}{ Mother's Occupation } \\
\hline Housewife & 17 & 2.5 \\
\hline Civil Servant & 87 & 12.8 \\
\hline Highly Skilled Professional & 130 & 19.1 \\
\hline Business & 247 & 36.2 \\
\hline Petty Trading & 24 & 25.9 \\
\hline Academics & 17 & 3.5 \\
\hline \multicolumn{3}{|l|}{ Father's Education Level } \\
\hline No Formal Education & 83 & 12.2 \\
\hline Primary & 44 & 6.5 \\
\hline Secondary & 199 & 29.1 \\
\hline Tertiary & 356 & 52.2 \\
\hline \multicolumn{3}{|l|}{ Mother's Education Level } \\
\hline No Formal Education & 95 & 13.9 \\
\hline Primary & 52 & 7.6 \\
\hline Secondary & 214 & 31.4 \\
\hline Tertiary & 321 & 47.1 \\
\hline Total & 682 & 100 \\
\hline
\end{tabular}


Table II: Respondents' nutritional knowledge

\begin{tabular}{|c|c|c|}
\hline Nutrition knowledge & Frequency $(n=682)$ & Percentage (\%) \\
\hline There are six (6) classes of food & 476 & 69.8 \\
\hline \multicolumn{3}{|l|}{ Knowledge of balanced diet } \\
\hline Contains essential nutrients & 477 & 69.9 \\
\hline Contains essential nutrients in proper quantities & 117 & 17.2 \\
\hline Important for good health & 88 & 12.9 \\
\hline Definition of nutrient & 535 & 78.5 \\
\hline Foods rich in protein & 519 & 76.1 \\
\hline Foods rich in carbohydrate & 558 & 81.8 \\
\hline Foods rich in fiber & 167 & 24.5 \\
\hline Foods rich in calcium & 456 & 66.9 \\
\hline Fruits and vegetables are rich in fibre\& vitamins & 357 & 52.4 \\
\hline Iodine fortified food item & 546 & 80.1 \\
\hline
\end{tabular}

Knowledge of foods that lead to overweight or obesity

\begin{tabular}{lcc}
\hline \multicolumn{1}{c}{ Drinking a lot of soft drinks } & 252 & 37 \\
\hline \multicolumn{1}{c}{ Drinking alcohol } & 91 & 13.3 \\
\hline Food can either cause disease or improve health & 339 & 49.7 \\
\hline Unit of measurement of food on label is Calorie (C) & 108 & 15.8 \\
\hline Causes of kwashiorkor & 198 & 29 \\
\hline Cause of rickets & 346 & 50.7 \\
\hline Sources of nutrition information & 216 & 31.7 \\
\hline Family members & & \\
\hline Friends and peers & 369 & 54.1 \\
\hline Online sources & 129 & 18.9 \\
\hline Traditional media & 298 & 43.7 \\
\hline Overall level of knowledge & 269 & 39.4 \\
\hline Good & & \\
\hline Fair & 82 & 12 \\
\hline Poor & 463 & 68 \\
\hline TOTAL & 137 & 20 \\
\hline
\end{tabular}

Table III: Factors associated with nutritional knowledge 
Sex

Male

17(4.3)

340(86.1)

$38(9.6)$

395(100) <0.001*

Female

$120(41.8)$

123(42.9)

44(15.3)

287(100)

\section{Educational level}

Junior secondary

Senior secondary

$7(2.0)$

312(89.4)

$30(8.6)$

$349(100)<0.001 *$

130(39.0)

151(45.4)

$52(15.6)$

333(100)

\section{Source of nutrition information}

Family $(\mathrm{n}=369)$

Online (n=298)

Peers(n=129)

120(32.5)

232(62.9)

17(4.6)

369(100)

Traditional media $(\mathrm{n}=269)$

$120(40.2)$

120(93.0)

$120(44.6)$
161(54.0)

$0(0.0)$

$132(49.1)$
17(5.7)

9(7.0)

17(6.3)
298(100) <0.001*

129(100)

269(100)

* Statistically significant

Table IV: Factors associated with the nutritional status of the adolescents 


\begin{tabular}{|c|c|c|c|c|c|c|c|}
\hline & Under-weight & Normal weight & Over-weight & Obesity & Total & $\mathrm{X} 2$ & P-value \\
\hline \multicolumn{8}{|l|}{ Sex } \\
\hline Male & $5(1.3)$ & $340(86.1)$ & $33(8.4)$ & $17(4.3)$ & $395(100)$ & 43.15 & $<0.001$ \\
\hline Female & $32(11.2)$ & 196(68.3) & 40(13.9) & $19(6.6)$ & $287(100)$ & & \\
\hline \multicolumn{8}{|c|}{ Age (years) } \\
\hline $10-14$ & 13(3.0) & $362(83.0)$ & $46(10.6)$ & 15(3.5) & $436(100)$ & 23.97 & $<0.001$ \\
\hline $15-19$ & 24(9.8) & 174(70.7) & $27(11.0)$ & $21(8.5)$ & $246(100)$ & & \\
\hline \multicolumn{8}{|c|}{ Currently living with } \\
\hline Parents & $37(5.7)$ & $501(77.4)$ & 73(11.3) & $36(5.6)$ & $647(100)$ & 10.05 & $0.0182 *$ \\
\hline Others & $0(0.0)$ & $35(100)$ & $0(0.0)$ & $0(0.0)$ & $35(100)$ & & \\
\hline \multicolumn{8}{|c|}{ Level of knowledge } \\
\hline Poor & $28(20.4)$ & $71(51.8)$ & $22(16.1)$ & 16(11.7) & 137(100) & 110.9 & $<0.001 *$ \\
\hline Fair & $7(1.5$ & $403(87.1)$ & $38(8.2)$ & $15(3.2)$ & $463(100)$ & & \\
\hline Good & $2(2.4)$ & $62(75.6)$ & 13(15.9) & $5(6.1)$ & $82(100)$ & & \\
\hline \multicolumn{8}{|c|}{ Daily intake of } \\
\hline \multicolumn{8}{|c|}{ Fruits \& Vegetables } \\
\hline No & $0(0.0)$ & $223(41.6)$ & 71(15.6) & $35(7.7)$ & $329(100)$ & 81.44 & $<0.001 *$ \\
\hline Yes & $37(8.1)$ & $313(68.6)$ & $2(2.7)$ & $1(2.8)$ & $353(100)$ & & \\
\hline \multicolumn{8}{|c|}{ Number of main meals eaten daily } \\
\hline$<3$ & $2(3.1)$ & $51(78.5)$ & $7(10.8)$ & $5(7.7)$ & $65(100)$ & & \\
\hline $03-4$ & $35(6.0)$ & $447(77.2)$ & $66(11.4)$ & $31(5.4)$ & $579(100)$ & 22.38 & $0.0508^{*}$ \\
\hline$>4$ & $0(0.0)$ & $38(100)$ & $0(0.0)$ & $0(0.0)$ & $38(100)$ & & \\
\hline \multicolumn{8}{|c|}{ Take soft drinks daily } \\
\hline No & $9(2.5)$ & $280(77.1)$ & $51(14.1)$ & $23(6.3)$ & $363(100)$ & & \\
\hline Yes & 28(8.8) & $256(80.3)$ & $22(6.9)$ & 13(4.1) & $319(100)$ & 22.38 & 0.0001 \\
\hline \multicolumn{8}{|c|}{ Skip breakfast } \\
\hline No & $37(8.1)$ & $317(69.4)$ & $68(14.9)$ & $35(7.7)$ & $457(100)$ & & \\
\hline Yes & $0(0.0)$ & 219(97.3) & $5(2.2)$ & $1(0.4)$ & $225(100)$ & 70.65 & $<0.001 *$ \\
\hline \multicolumn{8}{|c|}{ Skip lunch } \\
\hline No & $37(9.8)$ & $249(67.1)$ & 63(17.0) & $22(5.9)$ & $371(100)$ & 75.26 & $<0.001 *$ \\
\hline Yes & $0(0.0)$ & $287(92.3)$ & $10(3.2)$ & $14(4.5)$ & $311(100)$ & & \\
\hline \multicolumn{8}{|c|}{ Skip dinner } \\
\hline No & $37(5.8)$ & $492(77.4)$ & 71(11.2) & $36(5.7)$ & $636(100)$ & 8.97 & $0.0297 *$ \\
\hline Yes & $0(0.0)$ & $44(95.7)$ & $2(4.4)$ & $0(0.0)$ & $46(100)$ & & \\
\hline \multicolumn{8}{|c|}{ Control weight with dieting } \\
\hline Yes & $28(7.7)$ & $315(86.3)$ & 12(3.3) & $10(2.7)$ & $365(100)$ & 63.18 & $<0.001$ \\
\hline No & $9(2.8)$ & $221(69.7)$ & $61(19.2)$ & $26(8.2)$ & $317(100)$ & & \\
\hline
\end{tabular}


If yes, method used ( $n=363)$

\begin{tabular}{|c|c|c|c|c|c|c|c|}
\hline Skipping meals & $8(3.0)$ & 193(73.1) & $44(16.7)$ & $19(7.2)$ & $264(100)$ & & \\
\hline Laxatives/vomiting/diuretics & $1(2.6)$ & 28(71.8) & $5(12.8)$ & $5(12.8)$ & $39(100)$ & 206.44 & $<0.001 *$ \\
\hline Diet pills & $8(25.0)$ & $0(0.0)$ & $2(6.3)$ & $2(6.3)$ & $32(100)$ & & \\
\hline Avoiding high calorie meals & $20(71.4)$ & $8(28.6)$ & $0(0.0)$ & $0(0.0)$ & $28(100)$ & & \\
\hline \multicolumn{8}{|l|}{ Dietary diversity } \\
\hline Low & $36(7.6)$ & $336(70.7)$ & $68(14.3)$ & $35(7.4)$ & $475(100)$ & 57.69 & $<0.001 *$ \\
\hline High & $1(0.5)$ & 200(96.6) & $5(2.4)$ & $1(0.5)$ & $207(100)$ & & \\
\hline
\end{tabular}

*=Fisher's exact values, Row \% in bracket, Significant values $(\mathrm{p} \leq 0.05)$ highlighted.

\section{Figures}




\section{Food consumption pattern}

100

90

80

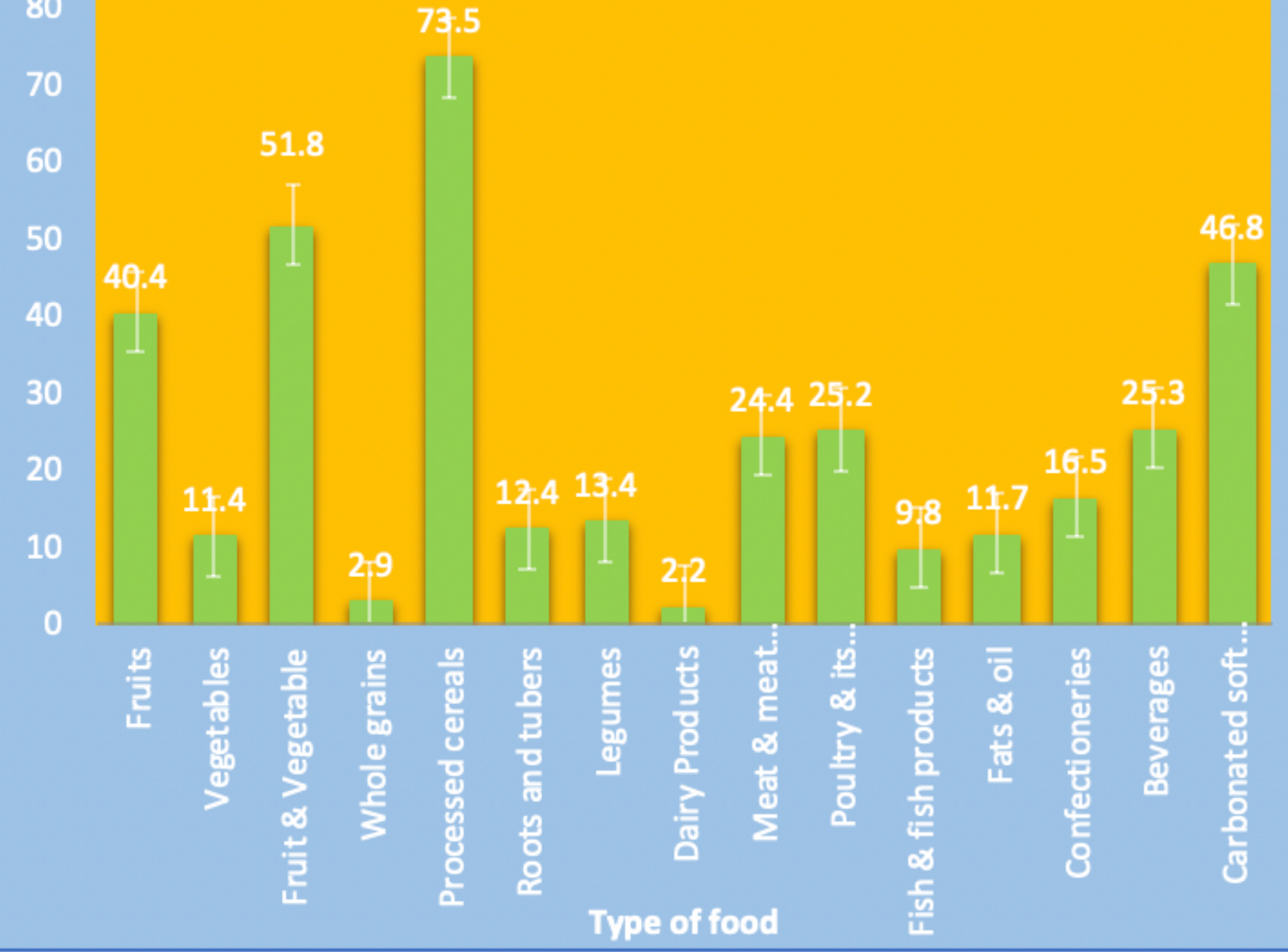

\section{Figure 1}

Respondents' food consumption pattern 


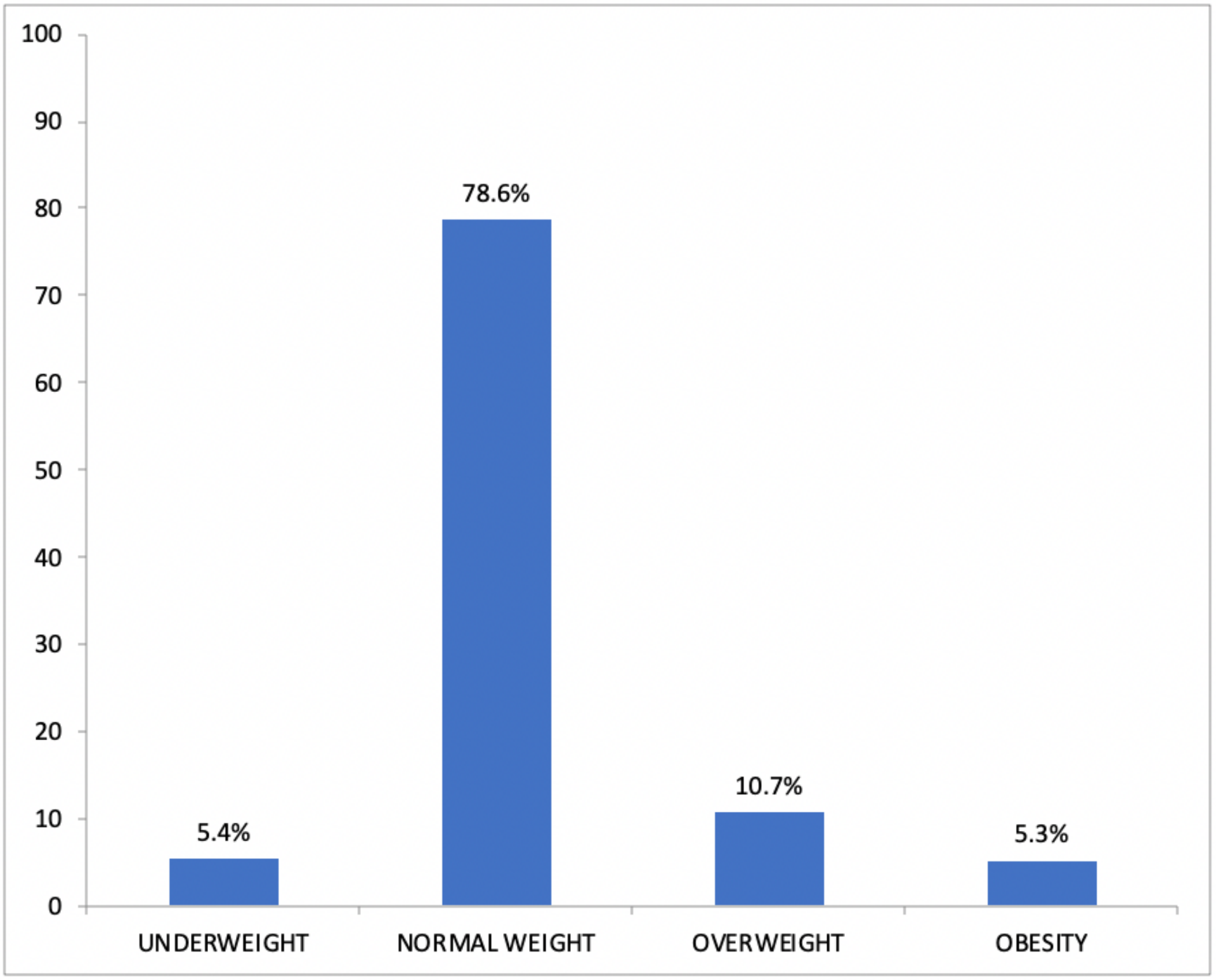

Figure 2

Nutritional Status of the adolescents 